\title{
The voice quality after laser surgery versus radiotherapy of T la glottic carcinoma: systematic review and meta-analysis
}

This article was published in the following Dove Press journal:

OncoTargets and Therapy

3 May 2017

Number of times this article has been viewed

\author{
Guanjiang Huang ${ }^{1, *}$ \\ Mengsi Luo ${ }^{2, *}$ \\ Jingxuan Zhang' \\ Hongbing Liu' \\ 'Department of Otolaryngology - \\ Head and Neck Surgery, ${ }^{2}$ Department \\ of Anesthesiology, The Second \\ Affiliated Hospital of Nanchang \\ University, Nanchang, Jiangxi, People's \\ Republic of China \\ *These authors contributed equally \\ to this work
}

Background and objectives: The voice quality assessment of laser surgery (LS) in comparison with radiotherapy (RT) remains uncertain in T1a glottic carcinoma treatment. This systematic review and meta-analysis were conducted to compare the voice quality of the two treatments.

Methods: Searches were conducted in PubMed, EMBASE, and Cochrane with the following index words: glotti*, layn*, vocal cord, vocal, surgery, cordectomy, laser, radiation, irradiation, radiotherapy, cancer, and carcinoma for relative studies that compared the voice quality between LS and RT. Random-effect models were used, and heterogeneity was assessed.

Results: A total of 14 studies were included in the analysis, consisting of 1 randomized controlled trial, 1 prospective study, and 12 retrospective studies. RT has increased the maximum phonation time (MPT; mean difference $[\mathrm{MD}]=-1.89,95 \%$ confidence interval $[\mathrm{CI}]=-3.66$ to $-0.11, P=0.04)$ and decreased the fundamental frequency $(\mathrm{MD}=14.06,95 \% \mathrm{CI}=10.30-17.83$, $P<0.00001)$ in comparison with LS. No statistical difference was observed between the two groups in terms of Voice Handicap Index, Jitter, Shimmer, and airflow rate.

Conclusion: RT may be a better choice for T1a glottic carcinoma treatment compared with LS because patients undergoing RT may have the advantage of increased MPT and decreased fundamental frequency. However, more multicenter, randomized, controlled trials are urgently needed to verify these differences.

Keywords: laser therapy, radiotherapy, meta-analysis, glottis, laryngeal neoplasms

\section{Introduction}

Laryngeal carcinoma is the most common malignant tumors of head and neck, and the majority of laryngeal carcinoma are confined within the glottic area., ${ }^{1,2}$ Owing to the involvement of the vocal folds, patients with glottic carcinoma always present with hoarseness in early stages. Therefore, glottic carcinoma can usually be diagnosed at the early stage and related treatment can often be achieved early., ${ }^{3,4}$

Laser surgery (LS), radiotherapy (RT), and open surgery all are accepted modalities of treatment for T1a glottic carcinoma. Open laryngectomy has been applied for $>100$ years. This method is still being used to cure T1a glottic carcinoma in locations that do not have access. Open surgery provides excellent exposure and has a higher rate of locoregional control, but voice quality is generally worse than that after RT or after LS. ${ }^{5-7}$ Furthermore, with the development of RT and the improvements in LS, open surgery is gradually being substituted. Therefore, open surgery should not be used any more for primary treatment of T1a glottic carcinoma. 
Nowadays, T1a glottic carcinoma is usually treated by LS or RT. Both LS and RT have good oncology and survival outcomes ${ }^{8,9}$ Low et al displayed a retrospective review covering all consecutive patients from 2003 to 2013; patients of T1 a glottic carcinoma were offered the options of either LS or RT. ${ }^{10}$ There were 105 patients, of whom 53 were treated with LS and 52 were treated with RT. The 5-year overall survival of patients with T1a glottic carcinoma treated with LM versus RT was $86 \%$ versus $85 \%(P=0.887)$, laryngectomy-free survival (LFS) was $65 \%$ versus $77 \%$ ( $P=0.198)$, laryngectomyfree disease-specific survival (LFS-DSS) was $100 \%$ versus $88 \%(P=0.030)$, disease-free survival was $69 \%$ versus $78 \%$ $(P=0.151)$, and ultimate locoregional control was $100 \%$ versus $100 \%$.

Thus, the treatment option of LS and RT for patients of T1a glottic carcinoma often depends on quality of life, particularly the voice quality. ${ }^{111-13}$ In this paper, this metaanalysis is conducted to compare the voice quality of LS and RT, which can help better patients of T1a glottic carcinoma to choose a reasonable treatment.

\section{Methods}

\section{Data sources and literature search strategy}

Literature review was separately conducted by two investigators (GJH and MSL) through online data sources PubMed, EMBASE, and Cochrane (up to October 2016), using the following index words: glotti*, layn*, vocal cord, vocal, surgery, cordectomy, laser, radiation, irradiation, radiotherapy, cancer, and carcinoma.

\section{Study selection}

Inclusion criteria were: 1) randomized controlled trials, prospective studies or retrospective studies; 2) patients who underwent first treatment for T1a glottic carcinoma; 3) comparing LS with RT on interest outcomes such as Voice Handicap Index (VHI), acoustic analysis, and perceptual analysis; and 4) written in English language.

\section{Study quality assessment}

Study quality assessment was all conducted by The NewcastleOttawa Quality Assessment Scale (NOS). The study that is considered as high quality is eligible for the research.

\section{Data extraction}

The data on characteristics of studies, VHI, and acoustic analysis were extracted from the selected studies by one author (GJH) and checked by another author (JXZ). Information included are study name, publication year, study design, number of patients, age, sex, tumor stage, follow-up time, VHI, and acoustic analysis.

\section{Statistical analysis}

Review Manager Version 5.3 was applied to perform this meta-analysis. Outcome data reported as mean \pm standard deviation (SD) were adopted, and mean difference (MD) was calculated. Continuous outcome variables were compared using weighted MD and 95\% confidence intervals (CIs). Heterogeneity of the studies was evaluated by the chi-squared statistic and publication bias by funnel plots, in which significance was set at $P<0.1$. The $I^{2}$ test was involved to measure the extent of inconsistency among results. The $\mathrm{z}$ statistic was used to test the overall pooled effect, and significance was set at $P<0.05$. All the statistical results use random-effect models. The subgroup analysis was conducted based on the study design.

\section{Results}

\section{Eligible studies and characteristics of studies}

In this meta-analysis, 14 studies were included: 1 randomized controlled trial, 1 prospective study, and 12 retrospective studies (Figure 1). Only one randomized controlled trial is included. A total of 701 patients were included in the research, of whom 395 (56\%) underwent LS and 306 (44\%) underwent RT. The characteristics of the included studies are shown in Table 1, and detailed data are shown in Tables 2 and 3.

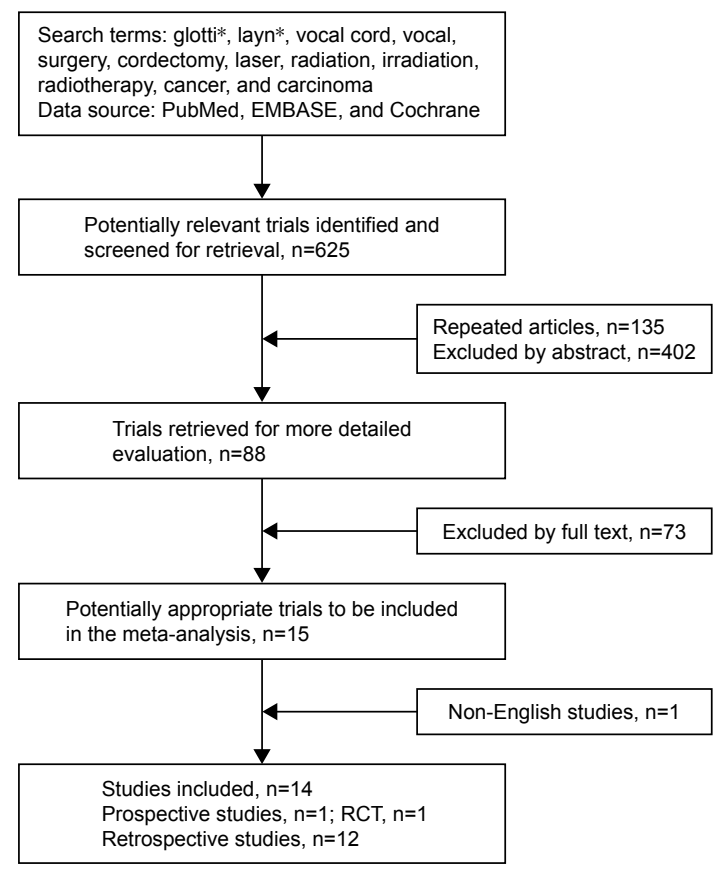

Figure I Stages of the systematic review of the trials. Abbreviation: RCT, randomized controlled trial. 
Table I Characteristics and demographics of included studies

\begin{tabular}{|c|c|c|c|c|c|c|c|c|c|c|c|c|c|c|c|c|c|}
\hline \multirow[t]{2}{*}{ Reference } & \multirow[t]{2}{*}{ Year } & \multirow[t]{2}{*}{ Design } & \multicolumn{2}{|c|}{$\begin{array}{l}\text { Group, } \\
\mathbf{n}\end{array}$} & \multicolumn{3}{|c|}{$\begin{array}{l}\text { Classification } \\
\text { of LS, } \mathbf{n}\end{array}$} & \multicolumn{3}{|c|}{$\begin{array}{l}\text { Classification } \\
\text { of } R T, n\end{array}$} & \multicolumn{2}{|c|}{$\begin{array}{l}\text { Male/ } \\
\text { female, n }\end{array}$} & \multicolumn{2}{|c|}{$\begin{array}{l}\text { Mean } \\
\text { age, years } \\
\end{array}$} & \multicolumn{2}{|c|}{$\begin{array}{l}\text { Follow-up } \\
\text { time, months }\end{array}$} & \multirow[t]{2}{*}{ NOS } \\
\hline & & & LS & RT & Tla & TIb & T2 & Tla & TIb & $\mathbf{T 2}$ & LS & RT & LS & $\mathbf{R T}$ & LS & RT & \\
\hline Cragle and & 1993 & Retrospective & 11 & 20 & II & 0 & 0 & 20 & 0 & 0 & $\mathrm{n} / \mathrm{a}$ & $\mathrm{n} / \mathrm{a}$ & $\mathrm{n} / \mathrm{a}$ & $\mathrm{n} / \mathrm{a}$ & $\geq 5.0$ & $\geq 5.0$ & 7 \\
\hline \multicolumn{18}{|l|}{ Brandenburg ${ }^{24}$} \\
\hline McGuirt et $\mathrm{a}^{25}$ & 1994 & Retrospective & 11 & 13 & II & 0 & 0 & 13 & 0 & 0 & $11 / 0$ & $13 / 0$ & $\mathrm{n} / \mathrm{a}$ & $\mathrm{n} / \mathrm{a}$ & $\geq 6.0$ & $\geq 6.0$ & 7 \\
\hline Rydell et $\mathrm{al}^{26}$ & 1995 & Retrospective & 18 & 18 & 18 & 0 & 0 & 18 & 0 & 0 & $18 / 0$ & $18 / 0$ & 65.2 & 63.9 & 24.0 & 24.0 & 7 \\
\hline Wedman et $\mathrm{a}^{27}$ & 2002 & Retrospective & 15 & 9 & 15 & 0 & 0 & 9 & 0 & 0 & $\mathrm{n} / \mathrm{a}$ & $\mathrm{n} / \mathrm{a}$ & $\mathrm{n} / \mathrm{a}$ & $\mathrm{n} / \mathrm{a}$ & $\geq 24.0$ & $\geq 24.0$ & 7 \\
\hline Tamura et $\mathrm{al}^{28}$ & 2003 & Retrospective & 14 & 6 & 14 & 0 & 0 & 6 & 0 & 0 & $14 / 0$ & $6 / 0$ & 69.0 & 71.0 & 26.3 & 21.3 & 6 \\
\hline Krengli et $\mathrm{al}^{29}$ & 2004 & Retrospective & 30 & 27 & 30 & 0 & 0 & 27 & 0 & 0 & $29 / 1$ & $26 / 1$ & 67.5 & 69.0 & 62.0 & 60.0 & 7 \\
\hline Peeters et $\mathrm{al}^{30}$ & 2004 & Retrospective & 52 & 40 & 52 & 0 & 0 & 40 & 0 & 0 & $47 / 5$ & $38 / 2$ & 66.0 & 64.0 & $\geq 12.0$ & $\geq 12.0$ & 7 \\
\hline Loughran et $\mathrm{a}^{31}$ & 2005 & Retrospective & 18 & 18 & 18 & 0 & 0 & 18 & 0 & 0 & $18 / 0$ & $18 / 0$ & 69.4 & 70.3 & 27.6 & 31.4 & 7 \\
\hline Goor et al $\left.\right|^{32}$ & 2007 & Retrospective & 54 & 35 & 54 & 0 & 0 & 35 & 0 & 0 & $49 / 5$ & $30 / 35$ & 67.4 & 63.8 & 24.0 & 24.0 & 7 \\
\hline Nunez et $\mathrm{al}^{33}$ & 2008 & Retrospective & 19 & 18 & 19 & 0 & 0 & 13 & 5 & 0 & $\mathrm{n} / \mathrm{a}$ & $\mathrm{n} / \mathrm{a}$ & 64.0 & 67.0 & 30.0 & 43.0 & 8 \\
\hline Sjogren et $\mathrm{al}^{15}$ & 2008 & Retrospective & 18 & 16 & 18 & 0 & 0 & 16 & 0 & 0 & $14 / 4$ & $13 / 3$ & 67.0 & 69.0 & 45.0 & 60.0 & 7 \\
\hline van Gogh et $\mathrm{al}^{34}$ & 2012 & Prospective & 67 & 39 & 67 & 0 & 0 & 39 & 0 & 0 & $67 / 0$ & $39 / 0$ & $\mathrm{n} / \mathrm{a}$ & $\mathrm{n} / \mathrm{a}$ & 24.0 & 24.0 & 8 \\
\hline Aaltonen et $\mathrm{al}^{16}$ & 2014 & $\mathrm{RCT}$ & 31 & 25 & 31 & 0 & 0 & 25 & 0 & 0 & $31 / 0$ & $25 / 0$ & 69.0 & 61.0 & 24.0 & 24.0 & 9 \\
\hline Kono et al ${ }^{14}$ & 2016 & Retrospective & 37 & 27 & 37 & 0 & 0 & 27 & 0 & 0 & $33 / 4$ & $22 / 5$ & $\mathrm{n} / \mathrm{a}$ & 69.0 & 24.0 & 37.0 & 8 \\
\hline
\end{tabular}

Abbreviations: LS, laser surgery; n, number of patients; n/a, not available; NOS, Newcastle-Ottawa Quality Assessment Scale; RCT, randomized controlled trial; RT, radiotherapy.

\section{Meta-analysis of postoperative outcomes} Voice Handicap Index

Among the included studies, only 5 studies provide detailed data on VHI with 162 patients in the LS group and 123 patients in the RT group. Heterogeneity was identified between the studies $\left(\mathrm{Chi}^{2}=25.26, P<0.0001, P=84 \%\right)$; therefore, a random-effects model was used to calculate the pooled effect. Results of the pooled effect showed that the difference between LS and RT with respect to the VHI was not statistically significant (test for subgroup differences: $\mathrm{MD}=5.86$, $95 \% \mathrm{CI}=-5.22$ to $16.84, P=0.30)$; in VHI (2004-2007) studies subgroup: $\mathrm{MD}=-5.32,95 \% \mathrm{CI}=-13.77$ to $3.14, P=0.22$, whereas in VHI (2008-2016) studies subgroup: $\mathrm{MD}=16.79$, $95 \% \mathrm{CI}=14.85$ to $18.74, P<0.00001$ (Figure 2).

\section{Acoustic analysis}

Among the included studies, 10 studies provide detailed data on acoustic analysis with 258 patients in the LS group and 224 patients in the RT group. RT has increased the maximum phonation time (MPT; $\mathrm{MD}=-1.89,95 \% \mathrm{CI}=-3.66$ to -0.11 , $P=0.04$; Figure $3 \mathrm{~A}$ ) and decreased the fundamental frequency

Table $2 \mathrm{VHI}$ of the two treatment groups in the included studies

\begin{tabular}{|c|c|c|c|c|c|c|}
\hline \multirow[t]{2}{*}{ Reference } & \multicolumn{3}{|c|}{ LS group } & \multicolumn{3}{|c|}{ RT group } \\
\hline & $n$ & Mean & SD & $n$ & Mean & SD \\
\hline Peeters et $\mathrm{al}^{30}$ & 52 & 12 & 30 & 40 & 18 & 26 \\
\hline Loughran et $\mathrm{a}^{31}$ & 18 & 22.2 & 24.6 & 18 & 25.4 & 24.7 \\
\hline Goor et a $\left.\right|^{32}$ & 36 & 10.6 & 32 & 20 & 17.1 & 38.7 \\
\hline Nunez et $\mathrm{al}^{33}$ & 19 & 28.79 & 19.8 & 18 & 9.67 & 9.1 \\
\hline Kono et $\mathrm{al}^{14}$ & 37 & 29.3 & 4.9 & 27 & 12.6 & 3.2 \\
\hline
\end{tabular}

Abbreviations: LS, laser surgery; $n$, number of patients; RT, radiotherapy; SD, standard deviation; VHI, Voice Handicap Index.
$\left(\mathrm{F}_{0}\right)(\mathrm{MD}=14.06,95 \% \mathrm{CI}=10.30$ to $17.83, P<0.00001$; Figure $3 \mathrm{~B}$ ) in comparison with LS. There are no statistical significances in Jitter (MD $=0.73,95 \% \mathrm{CI}=-0.37$ to 1.83 , $P<0.00001$; Figure 3C), Shimmer (MD $=0.93,95 \% \mathrm{CI}$ $=-0.81$ to $2.67, P<0.00001$; Figure $3 \mathrm{D}$ ), and airflow rate (AFR) (MD $=21.46,95 \% \mathrm{CI}=-78.79$ to $121.72, P<0.00001$; Figure 3E).

All outcomes of interest were listed in Table 4, and the funnel plots show the publication bias of the $\mathrm{F}_{0}$ (Figure 4).

\section{Perceptual analysis}

One important method of voice quality evaluation is the perceptual analysis by GRBAS scale, and three studies were included. Voice quality was assessed on the GRBAS scale, consisting of grade $(G)$, roughness $(R)$, breathiness $(B)$, asthenia $(A)$, and strain (S). Ratings of these five aspects of voice quality varied from 0 (normal) to 3 (extremely abnormal). ${ }^{14-16}$ The higher the score, the more dysphonic the voice. Kono et al ${ }^{14}$ proved that tissue loss because of LS causes incomplete closure, which in turn is related to breathiness. Sjogren et $\mathrm{al}^{15}$ reported that patients showed mainly a mixed pattern of roughness and breathiness after RT, whereas patients were characterized as predominantly breathy after LS. They discussed that a possible explanation for these differences may be related to differences in classification of roughness. Aaltonen et $a{ }^{16}$ reported that breathiness improved after RT over the 2-year observation period, whereas no improvement in any of the five voice quality measures of the GRBAS scale occurred in the TLS group.

\section{Discussion}

In 2009, the European Laryngological Society developed a classification of transoral laser vocal cord resection. ${ }^{17}$ 
Table 3 Acoustic analysis of the two treatment groups in the included studies

\begin{tabular}{|c|c|c|c|c|c|c|c|c|c|c|c|c|}
\hline \multirow[t]{2}{*}{ Reference } & \multicolumn{6}{|c|}{ LS group } & \multicolumn{6}{|c|}{ RT group } \\
\hline & $\mathbf{n}$ & MPT & $\mathbf{F}_{0}$ & AFR & Jitter & Shimmer & $n$ & MPT & $\mathbf{F}_{0}$ & AFR & Jitter & Shimmer \\
\hline Cragle and & 11 & $16.00 \pm 1.00$ & $\mathrm{n} / \mathrm{a}$ & $204.00 \pm 1.0$ & $\mathrm{n} / \mathrm{a}$ & $13.14 \pm 1.00$ & 20 & $17.50 \pm 1.00$ & $\mathrm{n} / \mathrm{a}$ & $142.00 \pm 1.00$ & $\mathrm{n} / \mathrm{a}$ & $14.46 \pm 1.00$ \\
\hline \multicolumn{13}{|l|}{ Brandenburg ${ }^{24}$} \\
\hline McGuirt et $\mathrm{al}^{25}$ & 11 & $|5.8| \pm 1.00$ & $157.0 \pm 1.00$ & $118.5 \pm 1.1$ & $0.74 \pm 1.00$ & $\mathrm{n} / \mathrm{a}$ & 13 & $19.26 \pm 1.00$ & $136.00 \pm 1.00$ & $177.21 \pm 1.10$ & $0.84 \pm 1.00$ & $\mathrm{n} / \mathrm{a}$ \\
\hline Rydell et $\mathrm{a}^{26}$ & 18 & $\mathrm{n} / \mathrm{a}$ & $125.0 \pm 1.00$ & $\mathrm{n} / \mathrm{a}$ & $1.20 \pm 1.50$ & $8.00 \pm 1.00$ & 18 & $\mathrm{n} / \mathrm{a}$ & $107.00 \pm 1.00$ & $\mathrm{n} / \mathrm{a}$ & $0.70 \pm 0.03$ & $8.25 \pm 0.50$ \\
\hline Wedman et $\mathrm{al}^{27}$ & 9 & $\mathrm{n} / \mathrm{a}$ & $144.0 \pm 20.00$ & $\mathrm{n} / \mathrm{a}$ & $8.67 \pm 2.89$ & $1.3 \mathrm{I} \pm 0.26$ & 15 & $n / a$ & $137.00 \pm 12.00$ & $\mathrm{n} / \mathrm{a}$ & $8.38 \pm 1.66$ & $1.68 \pm 0.31$ \\
\hline Tamura et $\mathrm{a}^{28}$ & 14 & $14.30 \pm 6.46$ & $169.0 \pm 37.83$ & $237 \pm 123.7$ & $1.13 \pm 0.85$ & $3.80 \pm 1.60$ & 6 & $18.06 \pm 3.48$ & $160.00 \pm 43.20$ & $165.00 \pm 73.88$ & $0.93 \pm 0.58$ & $2.82 \pm 1.78$ \\
\hline Krengli et $\mathrm{a}^{29}$ & 30 & $\mathrm{n} / \mathrm{a}$ & $134.5 \pm 33.39$ & $\mathrm{n} / \mathrm{a}$ & $5.90 \pm 5.70$ & $12.20 \pm 2.90$ & 27 & $\mathrm{n} / \mathrm{a}$ & $167.80 \pm 55.88$ & $\mathrm{n} / \mathrm{a}$ & $2.30 \pm 1.39$ & $8.00 \pm 4.32$ \\
\hline Nunez et $\mathrm{al}^{33}$ & 19 & $11.83 \pm 5.28$ & $|73.4 \pm 47.4|$ & $\mathrm{n} / \mathrm{a}$ & $0.44 \pm 0.24$ & $5.08 \pm 4.72$ & 18 & $8.63 \pm 3.23$ & $|99.04 \pm 5| .46$ & $\mathrm{n} / \mathrm{a}$ & $0.72 \pm 0.91$ & $4.07 \pm 4.09$ \\
\hline Sjogren et $\mathrm{al}^{15}$ & 18 & $\mathrm{n} / \mathrm{a}$ & $\mid 56.0 \pm 1.83$ & $\mathrm{n} / \mathrm{a}$ & $\mathrm{n} / \mathrm{a}$ & $\mathrm{n} / \mathrm{a}$ & 16 & $\mathrm{n} / \mathrm{a}$ & $145.00 \pm 2.74$ & $\mathrm{n} / \mathrm{a}$ & $\mathrm{n} / \mathrm{a}$ & $\mathrm{n} / \mathrm{a}$ \\
\hline van Gogh et $\mathrm{al}^{34}$ & 67 & $\mathrm{n} / \mathrm{a}$ & $|4| \pm 33$ & $\mathrm{n} / \mathrm{a}$ & $0.46 \pm 0.49$ & $5.28 \pm 3.19$ & 39 & $\mathrm{n} / \mathrm{a}$ & $124 \pm 29$ & $\mathrm{n} / \mathrm{a}$ & $0.62 \pm 0.62$ & $5.8 \mathrm{I} \pm 3.75$ \\
\hline Kono et $\mathrm{al}^{14}$ & 37 & $14.5 \pm 4.2$ & $180.6 \pm 16.6$ & $\mathrm{n} / \mathrm{a}$ & $4.13 \pm 0.63$ & $7.45 \pm 1.06$ & 27 & $18.1 \pm 4.7$ & $|67.2 \pm|||$. & $\mathrm{n} / \mathrm{a}$ & $1.64 \pm 0.34$ & $3.39 \pm 0.39$ \\
\hline
\end{tabular}

Abbreviations: AFR, air flow rate; $F_{0}$, fundamental frequency; $L S$, laser surgery; MPT, maximum phonation time; $n$, number of patients; $n / a$, not available; RT, radiotherapy.

Type I: resection of vocal cord mucosa; Type II: resection of vocal cord mucosa and acoustic ligament; Type III: resection of vocal cord mucosa, acoustic ligament, and part of the vocal cord; Type IV: total vocal resection, including glottic fissure; Type V: total vocal resection, including anterior or arytenoid cartilage or part of the glottis or part of the subglottic structure. LS has plenty of unique advantages. It can achieve precise cutting, bloodless operation, short operation time, and significantly reduce the recurrence rate. ${ }^{11,18-20}$ Besides, the length of hospital stay will be shortened, and the cost of hospitalization is greatly reduced. ${ }^{21}$

At the same time, RT for T1a glottic carcinoma is more and more important, which has obvious therapeutic effects on T1a glottic carcinoma. RT can protect the laryngeal function and also can achieve similar therapeutic effects of surgery for patients of T1a glottic carcinoma. ${ }^{10,13,19} \mathrm{With}$ the development of science and technology, modern RT technology tends to be more targeted accurately. Compared with conventional RT, modern RT technology can be accurately applied to the tumor location and reduce the damage to normal cells. ${ }^{22,23}$ Nowadays, RT has been the gold standard for T1a glottic carcinoma treatment, but gradually the use of LS has increased. Therefore, patient-related factors may be the most important when choosing the treatment option for T1a glottic carcinoma.

With respect to VHI, sensitivity testing was conducted by subgroup analysis because there is moderate heterogeneity among the studies. The studies are subgrouped by the published

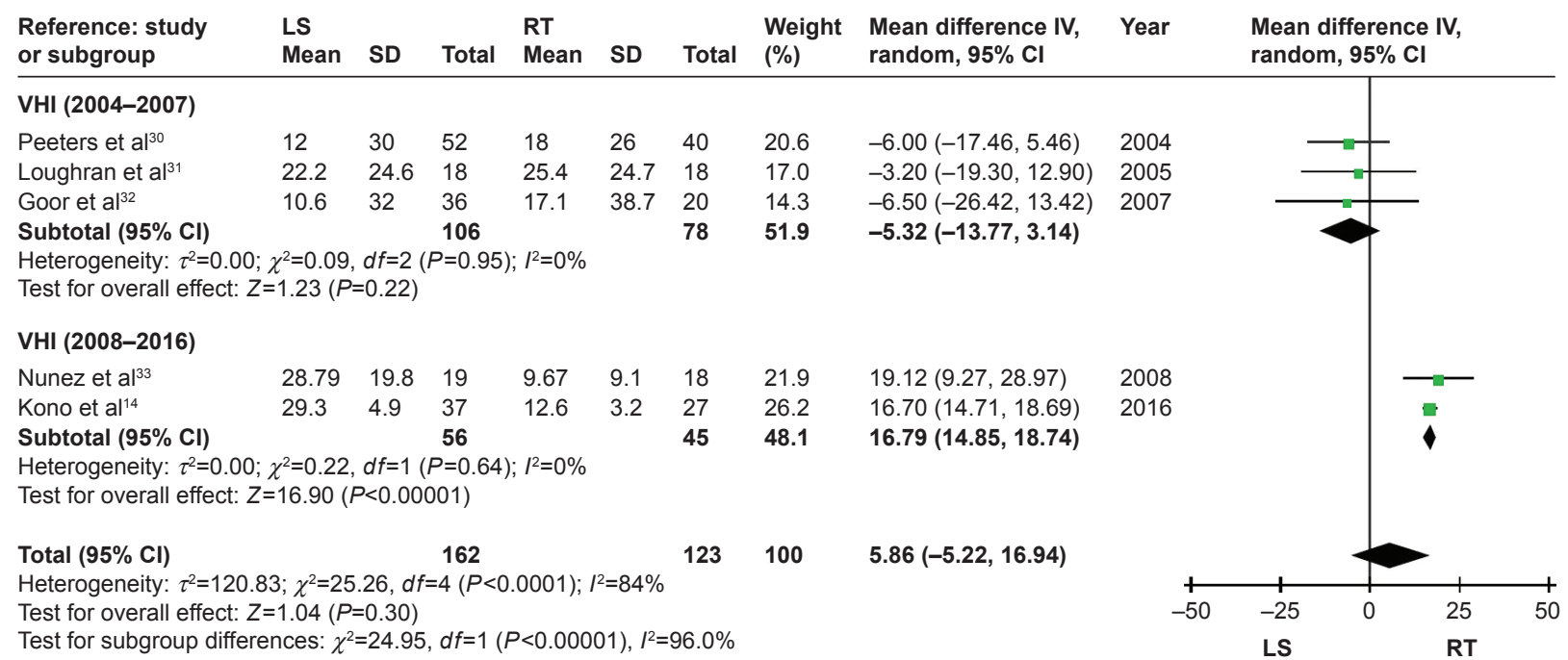

Figure 2 Forest plots of Voice Handicap Index (VHI).

Notes: The random-effects meta-analysis model (Mantel-Haenszel method) was used in this analysis. This is presented graphically as a black diamond, where the center of the diamond is the overall estimate and the width of the diamond is the overall confidence interval; the size of the green squares denotes the weight given to the study, with larger squares reflecting more weight.

Abbreviations: $\mathrm{Cl}$, confidence interval; IV, inverse variance; LS, laser surgery; RT, radiotherapy; SD, standard deviation. 


\begin{tabular}{|c|c|c|c|c|c|c|c|c|}
\hline $\begin{array}{l}\text { Reference: study } \\
\text { or subgroup }\end{array}$ & $\begin{array}{l}\text { LS } \\
\text { Mean }\end{array}$ & SD & Total & $\begin{array}{l}\text { RT } \\
\text { Mean }\end{array}$ & SD & Total & $\begin{array}{l}\text { Weight } \\
(\%)\end{array}$ & $\begin{array}{l}\text { Mean difference IV, } \\
\text { random, } 95 \% \mathrm{Cl}\end{array}$ \\
\hline Cragle and Brandenburg ${ }^{24}$ & 16 & 1 & 11 & 17.5 & 1 & 20 & 26.9 & $-1.50(-2.24,-0.76)$ \\
\hline McGuirt et al ${ }^{25}$ & 15.81 & 1 & 11 & 19.26 & 1 & 13 & 26.6 & $-3.45(-4.25,-2.65)$ \\
\hline Tamura et $\mathrm{al}^{28}$ & 14.3 & 6.46 & 14 & 18.06 & 3.48 & 6 & 10.4 & $-3.76(-8.14,0.62)$ \\
\hline Nunez et $a^{33}$ & 11.83 & 5.28 & 19 & 8.63 & 3.23 & 18 & 16.6 & $3.20(0.40,6.00)$ \\
\hline Kono et $\mathrm{al}^{14}$ & 14.5 & 4.2 & 37 & 18.1 & 4.7 & 27 & 19.5 & $-3.60(-5.83,-1.37)$ \\
\hline \multicolumn{3}{|c|}{ Total $(95 \% \mathrm{Cl})$} & \multicolumn{3}{|l|}{92} & 84 & 100 & $-1.89(-3.66,-0.11)$ \\
\hline \multicolumn{9}{|c|}{ Heterogeneity: $\tau^{2}=2.92 ; \chi^{2}=28.93, d f=4(P<0.00001) ; I^{2}=86 \%$} \\
\hline
\end{tabular}

\begin{tabular}{|c|c|c|c|c|c|c|c|c|}
\hline $\begin{array}{l}\text { B Reference: study } \\
\text { or subgroup }\end{array}$ & $\begin{array}{l}\text { LS } \\
\text { Mean }\end{array}$ & SD & Total & $\begin{array}{l}\text { RT } \\
\text { Mean }\end{array}$ & SD & Total & $\begin{array}{l}\text { Weight } \\
(\%)\end{array}$ & $\begin{array}{l}\text { Mean difference IV, } \\
\text { random, } 95 \% \mathrm{Cl}\end{array}$ \\
\hline McGuirt et $\mathrm{al}^{25}$ & 157 & 1 & 11 & 136 & 1 & 13 & 23.5 & $21.00(20.20,21.80)$ \\
\hline Rydell et $\mathrm{al}^{26}$ & 125 & 1 & 18 & 107 & 1 & 18 & 23.6 & $18.00(17.35,18.65)$ \\
\hline Wedman et al ${ }^{27}$ & 144 & 20 & 9 & 137 & 12 & 15 & 5.3 & $7.00(-7.41,21.41)$ \\
\hline Tamura et $\mathrm{al}^{28}$ & 169 & 37.83 & 14 & 160 & 43.2 & 6 & 0.9 & $9.00(-30.84,48.84)$ \\
\hline Krengli et al ${ }^{29}$ & 134.5 & 33.39 & 30 & 167.8 & 55.88 & 27 & 2.2 & $-33.30(-57.53,-9.07)$ \\
\hline Sjogren et al ${ }^{15}$ & 173.4 & 47.41 & 19 & 199.04 & 51.46 & 18 & 1.3 & $-25.64(-57.57,6.29)$ \\
\hline Nunez et $a^{33}$ & 156 & 1.83 & 18 & 145 & 2.74 & 16 & 22.8 & $11.00(9.41,12.59)$ \\
\hline van Gogh et al ${ }^{34}$ & 141 & 33 & 67 & 124 & 29 & 39 & 6.9 & $17.00(4.95,29.05)$ \\
\hline Kono et al ${ }^{14}$ & 180.6 & 16.6 & 37 & 167.2 & 11.1 & 27 & 13.4 & $13.40(6.61,20.19)$ \\
\hline \multicolumn{3}{|c|}{ Total $(95 \% \mathrm{Cl})$} & 223 & & & 179 & 100 & $14.06(10.30,17.83)$ \\
\hline \multicolumn{9}{|c|}{ Heterogeneity: $\tau^{2}=15.49 ; \chi^{2}=154.82, d f=8(P<0.00001) ; l^{2}=95 \%$} \\
\hline \multicolumn{9}{|c|}{ Test for overall effect: $Z=7.32(P<0.00001)$} \\
\hline
\end{tabular}

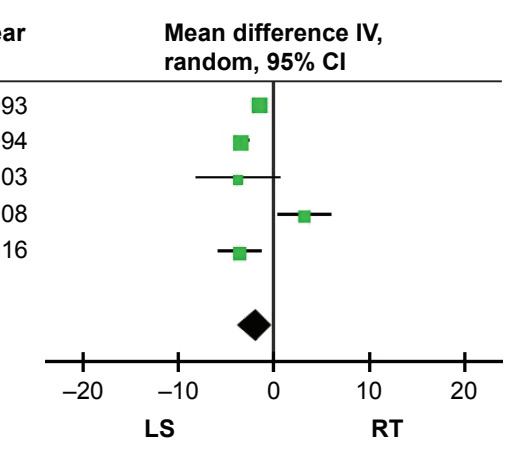

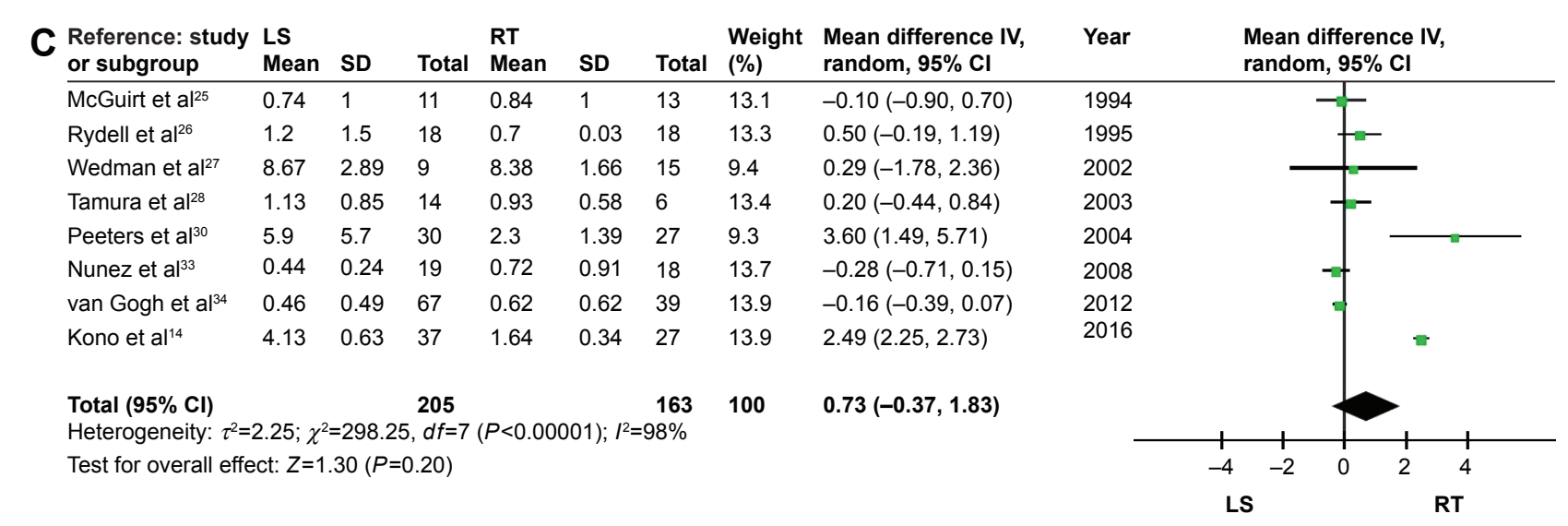

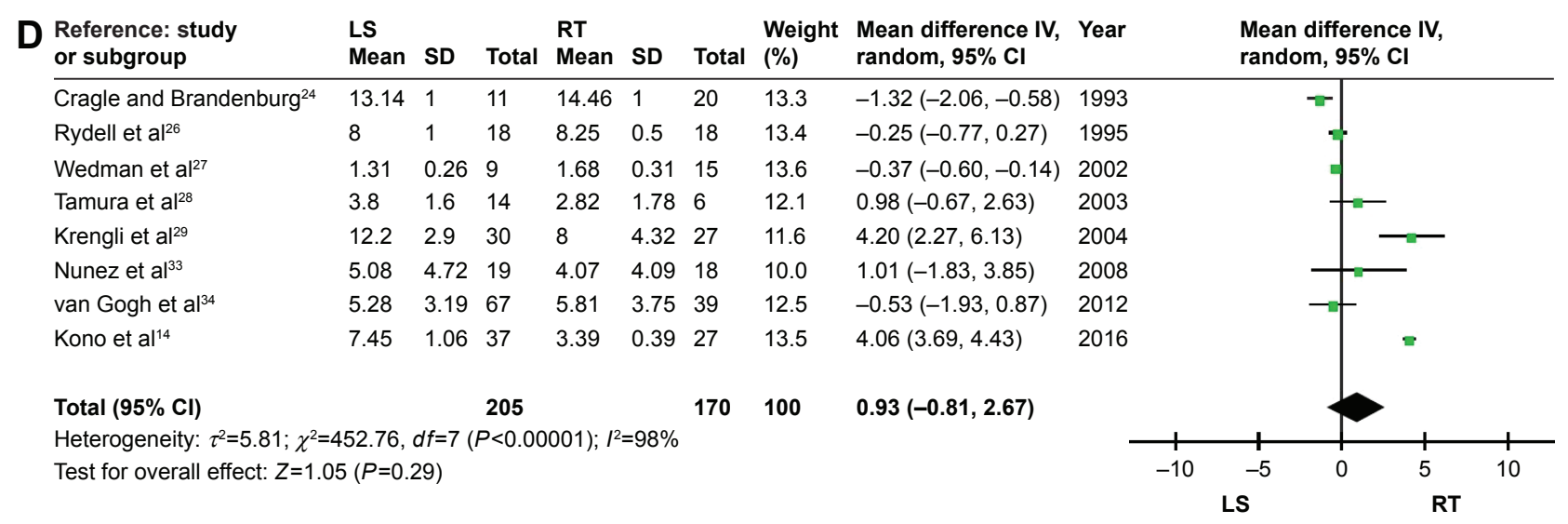

Figure 3 (Continued) 


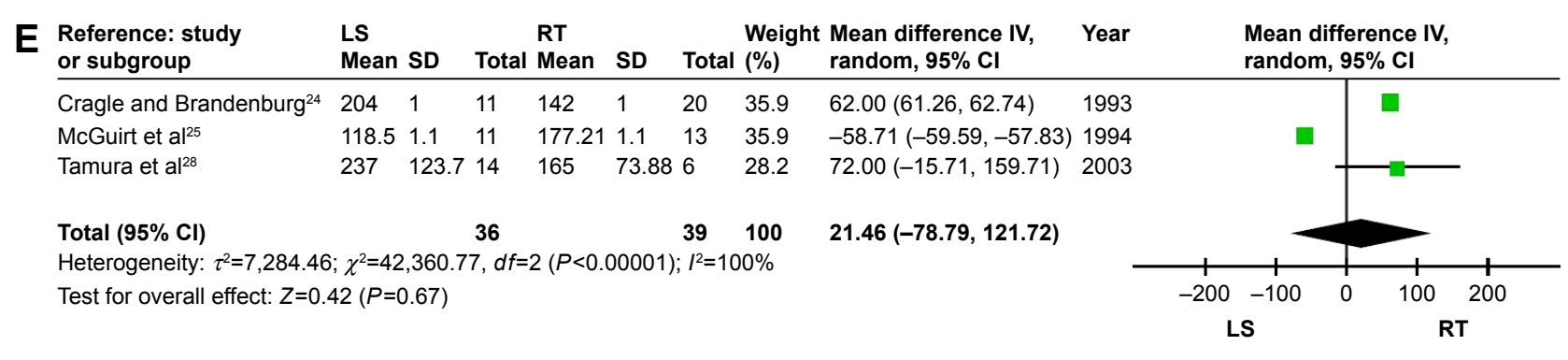

Figure 3 Forest plots of acoustic analysis outcomes.

Notes: Forest plots of (A) MPT, (B) $F_{0}$, (C) Jitter, (D) Shimmer, and (E) AFR. The random-effects meta-analysis model (Mantel-Haenszel method) was used in this analysis. This is presented graphically as a black diamond, where the center of the diamond is the overall estimate and the width of the diamond is the overall confidence interval; the size of the green squares denotes the weight given to the study, with larger squares reflecting more weight.

Abbreviations: AFR, air flow rate; $\mathrm{Cl}$, confidence interval; $\mathrm{F}_{0}$, fundamental frequency; IV, inverse variance; LS, laser surgery; MPT, maximum phonation time; RT, radiotherapy; $\mathrm{SD}$, standard deviation.

year. The pooled effect of studies published before 2007 shows no significant difference for VHI between the two treatment modalities. However, a different result is gained in the metaanalysis on studies published after 2008, which shows that VHI is significantly higher in patients treated with LS than that in those treated with RT, which proves that RT may be superior than LS on VHI. This demonstrates the fact that from the last decade, modern RT technology for T1a glottic carcinoma is becoming increasingly mature.

This meta-analysis of the parameters of acoustic analysis displayed that there is no significant difference between patients treated with LS and RT with respect to AFR, Jitter, and Shimmer. Only in the meta-analysis of MPT and $\mathrm{F}_{0}$, differences between patients treated with LS and RT are proved to be statistically significant. When comparing parameters of acoustic analysis between LS and RT, MPT is analyzed alone because MPT offers favorable outcomes, whereas the other parameters lead to unfavorable outcomes. Therefore, we could cautiously speculate that RT may be superior than LS on VHI.

With respect to perceptual analysis, overall voice quality was almost similar in RT group and LS group, however, indicating a need for careful consideration of patient-related factors to choose the treatment option. The vocal cord defect is caused by carcinoma, and TLS frequently causes longlasting voice impairment. ${ }^{16}$ Yet, individual compensation is an important factor contributing to final voice quality, and it may sometimes lead to an excellent voice. ${ }^{15}$

However, we still have some limitations for such this meta-analysis: 1) the sample number of the analysis is relatively low, and selection bias could be excluded; 2) only one randomized controlled trial is included, and the proportion of the prospective study is relatively small. Most of them are retrospective studies, which undoubtedly led to the increase in the heterogeneity of our analysis; 3 ) the studies included lacked detailed information on the radiation dose for RT and different types of the laser equipment for LS, which may also cause additional heterogeneity; 4) the treatment of a patient generally depends on the doctors' preferences or the patient's wishes; the follow-up times and sample sizes were also inconsistent; 5) the aforementioned factors lacked unified standards, and thus, may have had an uncertain impact on the final results.

Our results show no statistically significant differences in most of VHI and the acoustic outcomes between patients of T1a glottic carcinoma treated with LS and those treated with RT. Although data do not reach a level of statistical significance, there is a mild tendency in all parameters that favors RT. This finding should be cautiously speculated because of significant heterogeneity among the included studies, which could be originated from limited quality attributed to variable reporting, small sample size, and various types of

Table 4 Summary statistics of pooled data comparing LS versus RT

\begin{tabular}{|c|c|c|c|c|c|c|}
\hline Outcome & $\begin{array}{l}\text { Number } \\
\text { of studies }\end{array}$ & $\begin{array}{l}\text { Number of } \\
\text { cases }\end{array}$ & MD & $95 \% \mathrm{Cl}$ & Heterogeneity & $\begin{array}{l}\text { Test for } \\
\text { overall effect }\end{array}$ \\
\hline $\mathrm{VHI}$ & 5 & 285 & 5.86 & $-5.22,16.94$ & $P<0.0000 I, I^{2}=96.0 \%$ & $Z=1.04, P=0.30$ \\
\hline MPT & 5 & 176 & -1.89 & $-3.66,-0.11$ & $P<0.0000 \mathrm{I}, I^{2}=86 \%$ & $Z=2.08, P=0.04$ \\
\hline $\mathrm{F}_{0}$ & 9 & 402 & 14.06 & $10.30,17.83$ & $P<0.0000 I, I^{2}=95 \%$ & $Z=7.32, P<0.0000 \mathrm{I}$ \\
\hline AFR & 3 & 75 & 21.46 & $-78.79,121.72$ & $P<0.00001, I^{2}=100 \%$ & $Z=0.42, P=0.67$ \\
\hline Jitter & 8 & 368 & 0.73 & $-0.37,1.83$ & $P<0.0000 I, I^{2}=98 \%$ & $Z=1.30, P=0.20$ \\
\hline Shimmer & 8 & 375 & 0.93 & $-0.8 \mathrm{I}, 2.67$ & $P<0.0000 I, I^{2}=98 \%$ & $Z=1.05, P=0.29$ \\
\hline
\end{tabular}

Abbreviations: AFR, air flow rate; $\mathrm{Cl}$, confidence interval; $\mathrm{F}_{0}$, fundamental frequency; $\mathrm{LS}$, laser surgery; MD, mean difference; MPT, maximum phonation time; $\mathrm{RT}$, radiotherapy; VHI, Voice Handicap Index. 


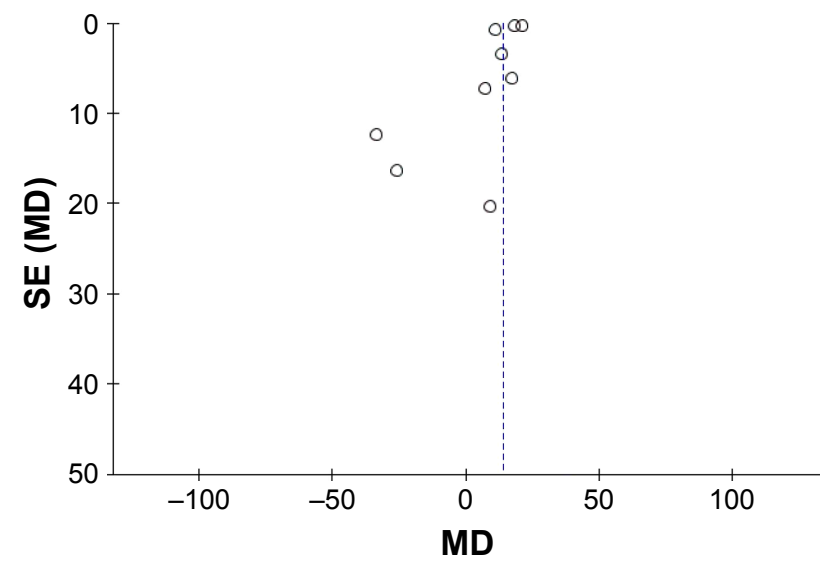

Figure 4 Publication bias: funnel plots of $\mathrm{F}_{0}$.

Abbreviations: $F_{0}$, fundamental frequency; $M D$, mean difference; $S E$, standard error.

biases discussed. Therefore, the work needs to be improved when there are more large, multicenter, and randomized controlled trials.

\section{Conclusion}

Patients who had undergone RT have increased MPT and decreased $\mathrm{F}_{0}$ in comparison with LS. No statistical difference was observed between the two groups in terms of VHI, Jitter, Shimmer, and AFR. In conclusion, RT may be a better choice for T1a glottic carcinoma treatment, and patient-related factors may be the most important when choosing the treatment option for T1a glottic carcinoma. To confirm our findings, more large, multicenter, and randomized controlled trials are urgently needed.

\section{Disclosure}

The authors report no conflicts of interest in this work.

\section{References}

1. Lee HS, Kim JS, Kim SW, et al. Voice outcome according to surgical extent of transoral laser microsurgery for T1 glottic carcinoma. Laryngoscope. 2016;126(9):2051-2056.

2. Ahn SH, Hong HJ, Kwon SY, et al. Guidelines for the Surgical Management of Laryngeal Cancer: Korean Society of Thyroid-Head and Neck Surgery. Clin Exp Otorhinolaryngol. 2017;10(1):1-43.

3. Eskiizmir G, Baskin Y, Yalcin F, Ellidokuz H, Ferris RL. Risk factors for radiation failure in early-stage glottic carcinoma: a systematic review and meta-analysis. Oral Oncol. 2016;62:90-100.

4. Peng Z, Li Y, Jin L, et al. Retrospective analysis of therapeutic effect and prognostic factors on early glottic carcinoma. Photodiagnosis Photodyn Ther. 2016;15:167-171.

5. Lucioni M, Bertolin A, Lionello M, et al. Open partial horizontal laryngectomy for salvage after failure of $\mathrm{CO}_{2}$ laser-assisted surgery for glottic carcinoma. Eur Arch Otorhinolaryngol. 2016;273(1):169-175.

6. Succo G, Crosetti E, Bertolin A, et al. Benefits and drawbacks of open partial horizontal laryngectomies, part A: early- to intermediate-stage glottic carcinoma. Head Neck. 2016;38(Suppl 1):E333-E340.

7. El OuakifF, Veresezan O. [Functional comparison of the voice quality after either open conservative surgery or only radiotherapy for early glottic carcinoma]. Rev Laryngol Otol Rhinol (Bord). 2015;136(1):17-20. French.
8. Comert E, Tuncel U, Dizman A, Guney YY. Comparison of early oncological results of diode laser surgery with radiotherapy for early glottic carcinoma. Otolaryngol Head Neck Surg. 2014;150(5):818-823.

9. Murono S, Endo K, Kondo S, Wakisaka N, Yoshizaki T. Oncological and functional outcome after transoral 532-nm pulsed potassium-titanylphosphate laser surgery for T1a glottic carcinoma. Lasers Med Sci. 2013;28(2):615-619.

10. Low TH, Yeh D, Zhang T, et al. Evaluating organ preservation outcome as treatment endpoint for T1aN0 glottic cancer. Laryngoscope. 2016. Epub October 25, 2016.

11. Day AT, Sinha P, Nussenbaum B, et al. Management of primary T1-T4 glottic squamous cell carcinoma by transoral laser microsurgery. Laryngoscope. 2017;127(3):597-604.

12. Greulich MT, Parker NP, Lee P, Merati AL, Misono S. Voice outcomes following radiation versus laser microsurgery for $\mathrm{T} 1$ glottic carcinoma: systematic review and meta-analysis. Otolaryngol Head Neck Surg. 2015;152(5):811-819.

13. Canis M, Ihler F, Martin A, et al. Transoral laser microsurgery for T1a glottic cancer: review of 404 cases. Head Neck. 2014;37(6):889-895.

14. Kono T, Saito K, Yabe H, Uno K, Ogawa K. Comparative multidimensional assessment of laryngeal function and quality of life after radiotherapy and laser surgery for early glottic cancer. Head Neck. 2016; 38(7):1085-1090.

15. Sjogren EV, van Rossum MA, Langeveld TP, et al. Voice outcome in T1a midcord glottic carcinoma: laser surgery vs radiotherapy. Arch Otolaryngol Head Neck Surg. 2008;134(9):965-972.

16. Aaltonen LM, Rautiainen N, Sellman J, et al. Voice quality after treatment of early vocal cord cancer: a randomized trial comparing laser surgery with radiation therapy. Int J Radiat Oncol Biol Phys. 2014; 90(2):255-260.

17. Remacle M, Eckel HE, Antonelli A, et al. Endoscopic cordectomy. A proposal for a classification by the Working Committee, European Laryngological Society. Eur Arch Otorhinolaryngol. 2000;257(4): 227-231.

18. van Loon Y, Stiggelbout AM, Hakkesteegt MM, Langeveld TP, de Jong RJ, Sjogren EV. Utility approach to decision-making in extended T1 and limited T2 glottic carcinoma. Head Neck. 2017;39(4): 779-785.

19. Mo HL, Li J, Yang X, et al. Transoral laser microsurgery versus radiotherapy for T1 glottic carcinoma: a systematic review and meta-analysis. Lasers Med Sci. 2017;32(2):461-467.

20. Chiesa EC, Reinoso FA, Velasquez AO, Fernandez JL, Conde JL, Hidalgo CS. Transoral CO2 laser microsurgery outcomes for early glottic carcinomas T1-T2. Int Arch Otorhinolaryngol. 2016;20(3): 212-217.

21. Prettyjohns M, Winter S, Kerawala C, Paleri V. Transoral laser microsurgery versus radiation therapy in the management of T1 and T2 laryngeal glottic carcinoma: which modality is cost-effective within the UK? Clin Otolaryngol. 2017;42(2):404-415.

22. Ermis E, Teo M, Dyker KE, Fosker C, Sen M, Prestwich RJ. Definitive hypofractionated radiotherapy for early glottic carcinoma: experience of 55Gy in 20 fractions. Radiat Oncol. 2015;10:203.

23. Higashino M, Kawata R, Lee K, Nishikawa S, Ichihara S, Uesugi Y Radiotherapy concurrent with $\mathrm{S}-1$ and radiotherapy alone for T2N0 glottic carcinoma: a retrospective comparative study. Auris Nasus Larynx. 2014;41(4):364-368.

24. Cragle SP, Brandenburg JH. Laser cordectomy or radiotherapy: cure rates, communication, and cost. Otolaryngol Head Neck Surg. 1993;108(6): 648-654.

25. McGuirt WF, Blalock D, Koufman JA, et al. Comparative voice results after laser resection or irradiation of T1 vocal cord carcinoma. Arch Otolaryngol Head Neck Surg. 1994;120(9):951-955.

26. Rydell R, Schalen L, Fex S, Elner A. Voice evaluation before and after laser excision vs radiotherapy of T1A glottic carcinoma. Acta Otolaryngol. 1995;115(4):560-565.

27. Wedman J, Heimdal JH, Elstad I, Olofsson J. Voice results in patients with T1a glottic cancer treated by radiotherapy or endoscopic measures. Eur Arch Otorhinolaryngol. 2002;259(10):547-550. 
28. Tamura E, Kitahara S, Ogura M, Kohno N. Voice quality after laser surgery or radiotherapy for T1 a glottic carcinoma. Laryngoscope. 2003; 113(5):910-914.

29. Krengli M, Policarpo M, Manfredda I, et al. Voice quality after treatment for T1a glottic carcinoma - radiotherapy versus laser cordectomy. Acta Oncol. 2004;43(3):284-289.

30. Peeters AJ, van Gogh CD, Goor KM, Verdonck-de Leeuw IM, Langendijk JA, Mahieu HF. Health status and voice outcome after treatment for T1a glottic carcinoma. Eur Arch Otorhinolaryngol. 2004; 261(10):534-540.

31. Loughran S, Calder N, Macgregor FB, Carding P, MacKenzie K. Quality of life and voice following endoscopic resection or radiotherapy for early glottic cancer. Clin Otolaryngol. 2005;30(1):42-47.
32. Goor KM, Peeters AJ, Mahieu HF, et al. Cordectomy by CO2 laser or radiotherapy for small T1a glottic carcinomas: costs, local control, survival, quality of life, and voice quality. Head Neck. 2007;29(2): $128-136$.

33. Nunez BF, Caminero CM, Senaris GB, et al. Voice quality after endoscopic laser surgery and radiotherapy for early glottic cancer: objective measurements emphasizing the Voice Handicap Index. Eur Arch Otorhinolaryngol. 2008;265(5):543-548.

34. van Gogh CD, Verdonck-De LI, Wedler-Peeters J, Langendijk JA, Mahieu HF. Prospective evaluation of voice outcome during the first two years in male patients treated by radiotherapy or laser surgery for T1a glottic carcinoma. Eur Arch Otorhinolaryngol. 2012; 269(6):1647-1652.
OncoTargets and Therapy

\section{Publish your work in this journal}

OncoTargets and Therapy is an international, peer-reviewed, open access journal focusing on the pathological basis of all cancers, potential targets for therapy and treatment protocols employed to improve the management of cancer patients. The journal also focuses on the impact of management programs and new therapeutic agents and protocols on

\section{Dovepress}

patient perspectives such as quality of life, adherence and satisfaction. The manuscript management system is completely online and includes a very quick and fair peer-review system, which is all easy to use. Visit http://www.dovepress.com/testimonials.php to read real quotes from published authors. 